\title{
Idiopathic Postural Hypotension: Physiologic Observations and Report of a New Mode of Therapy
}

\author{
Morton A. Diamond, Raymond H. Murray, and Philut G. Schmid \\ From the Departments of Medicine, Indiana University Medical Center, \\ Indianapolis, Indiana 46202, and University of Iowa School of Medicine, \\ Iowa City, Iowa 52240
}

A B S T R A C T Two patients with severe postural hypotension associated with upper motor neuron and cerebellar impairment (Shy-Drager syndrome) have been studied. Head-up tilt and lower body negative pressure application caused marked falls in arterial pressure; in one patient, paradoxical vasodilatation was observed. Ice application did not increase arterial pressure or calculated forearm vascular resistance. Intravenous atropine in one patient increased heart rate by 18 beats per min, a cardioacceleratory response similar to exhausting recumbent exercise in that patient. $24 \mathrm{hr}$ urinary catecholamine excretion was low, but aldosterone secretory rate was normal in the more severely afflicted patient. A prolonged elevation of plasma renin activity was noted when post-tilt hypertension occurred. When head-up tilt was not followed by this hypertensive period, plasma renin activity response to tilting was normal. Intraarterial norepinephrine and tyramine both elicited a vasoconstrictor response. Intra-arterial infusions of norepinephrine and tyramine were repeated after administration of the monoamine oxidase inhibitor tranylcypromine. Norepinephrine was potentiated 4.1- and 0.5 -fold in the two patients; tyramine was potentiated 3.7-and 1.1-fold in the two patients, respectively. A therapeutic program of tranylcypromine and tyramine (in the form of cheddar cheese) resulted in substantial clinical improvement. It is concluded that in at least some patients with idiopathic postural hypotension, norepinephrine is present in postganglionic sympathetic fibers. A therapeutic program of tyramine and a monoamine oxi-

This work was presented in part at the National Meeting of the American Federation for Clinical Research, 5 May 1969, Atlantic City, N. J., and has been published in abstract form (1).

This study was performed during Dr. Diamond's tenure as a Public Health Service Fellow.

Received for publication 24 November 1969 and in revised form 25 February 1970. dase inhibitor may be of value when more conventional modes of therapy fail.

\section{INTRODUCTION}

Although impaired arteriolar and venous constriction has been noted in idiopathic postural hypotension, the exact mechanism responsible has not been elucidated (2-6). This report studies the pathophysiologic mechanism related to impaired vasoconstriction, and further describes a new mode of therapy.

\section{METHODS}

Two men, aged 45 and 49 , with idiopathic postural hypotension have been studied. Both patients were strikingly similar in regard to historical features, progression of disease, physical examination, physiologic testing, and finally, response to therapy. In both, there was a $4 \mathrm{yr}$ history of anhydrosis, impotence, urinary incontinence, constipation, postural hypotension, and incoordination. Physical examination demonstrated the severe postural hypotension as well as upper motor neuron and cerebellar damage, suggesting that they fit into the clinically recognized Shy-Drager variant of this syndrome $(7,8)$. Unsuccessful earlier therapy in both patients had included mineralocorticoids, sympathomimetic amines, Jobst pressure garments, and high salt intake. Up to $1 \mathrm{mg} /$ day of $9-\alpha$-fluorohydrocortisone was given to the patients. In both, marked peripheral edema was noted without any significant lessening of orthostatic hypotension. The older patient, W. L., was so incapacitated by his orthostatic hypotension that he had been essentially bedridden for 1 yr prior to the present study. Patient $C$. $H$. could sit without apparent difficulty, but standing evoked syncope.

Reproducible study conditions were assured by constant supervision on the Metabolic Research Ward where a measured $4 \mathrm{~g}$ sodium diet was given during testing procedures. Throughout the period of study, careful monitoring of activity, blood pressure, and heart rate was achieved.

$24 \mathrm{hr}$ urinary epinephrine and norepinephrine excretion was measured utilizing a fluorometric technique (9). ${ }^{1}$ Plasma

${ }^{1}$ Kindly performed by Dr. T. E. Gaffney, University of Cincinnati College of Medicine. 
renin activity response to head-up tilting was performed after $12 \mathrm{hr}$ of recumbency, by the method of Helmer and Judson (10). $24 \mathrm{hr}$ aldosterone secretory rate was determined in a constant temperature ward after the patient had received a diet containing $43.5 \mathrm{mEq}$ of sodium per day for 5 days. The patient then received 2 liters of normal saline from 10 a.m. to 2 p.m. on each of 2 successive days. Aldosterone secretory rates were measured on the day before saline infusion and on the second infusion day. The method of Kliman and Peterson was followed (11).

The test procedures were designed to determine the degree of orthostatic impairment and the functional integrity of the adrenergic nervous system. In all tests, heart rate was determined from a continuously running electrocardiogram. Blood pressure was recorded by means of an indwelling arterial catheter placed in the subclavian artery by means of a percutaneous brachial artery puncture, or by the cuffauscultatory method; both techniques for measuring blood pressure were found to give similar results.

Blood pressure and heart rate were monitored during head-up tilt to $60^{\circ}$, graded lower body negative pressure (LBNP) to $-60 \mathrm{~mm} \mathrm{Hg}$ (12), immersion of a hand in ice water for $5 \mathrm{~min}$, supine leg exercise to a state of fatigue, using a bicycle ergometer, and during the intravenous administration of $2 \mathrm{mg}$ of atropine. Reflexly induced changes in forearm venous tone were elicited during ice application to the forehead, the Valsalva maneuver, and deep breathing. Forearm vascular responses were determined using plethysmographic techniques $(13,14)$. During combined tyraminemonoamine oxidase (MAO) inhibitor therapy, blood pressure and heart rate responses to head-up tilt, lower body negative pressure, and cold pressor test were retested. The observations of forearm vascular responses to lower body negative pressure were repeated.

Pharmacologic tests before and during tyramine-MAO inhibitor therapy were conducted. Patients were brought to the laboratory in a fasting state and during a comparable hour of the day. Forearm blood flow was measured with a mercury-in-rubber strain gauge plethysmograph (15). Blood pressure was measured from the brachial artery using a small catheter (PE 90) and strain gauge transducer $(\mathrm{P} 23 \mathrm{Db})$. Anesthesia for percutaneous insertion of the catheter was placed intradermally to avoid disturbing major nerves in the forearm. It is unlikely that the catheter interfered significantly with blood flow through the forearm in these experiments because: $(a)$ the outer diameter of the catheter, $1.27 \mathrm{~mm}$, was small in comparison to the lumen diameter of the artery; $(b)$ smaller arteries downstream to the catheter are functionally the significant resistance vessels which regulate limb blood flow (16); and $(c)$ observations of blood flow before and during treatment were made with the small catheter in the brachial artery so that conditions were comparable in the control and test conditions. Forearm vascular resistance was calculated as the ratio of mean arterial pressure $(\mathrm{mm} \mathrm{Hg})$ to forearm blood flow $(\mathrm{ml} / \mathrm{min} /$ $100 \mathrm{ml}$ forearm) and is expressed in arbitrary units.

Intravenous norepinephrine was given in concentrations of $0.0375,0.075$, and $0.15 \mu \mathrm{g}$ base $/ \mathrm{kg}$ body weight per $\mathrm{min}$; intravenous tyramine was infused in concentrations of 9,18 , and $36 \mu \mathrm{g}$ base $/ \mathrm{kg}$ per min. Doses used for intra-arterial norepinephrine and tyramine were $0.0375,0.075$, and 0.15 and 9,18 , and $36 \mu \mathrm{g}$ base/min, respectively. Arterial blood pressure and forearm blood flow determinations in response to norepinephrine and tyramine were performed again after 2 wk administration of the monoamine oxidase (MAO) inhibitor tranylcypromine, $60 \mathrm{mg} /$ day. A 4 point parallel line bioassay was used to estimate the change in potency induced by monoamine oxidase inhibition (17). Brachial artery blood pressure and forearm blood flow also were observed in 44 separate studies on 31 healthy normal volunteers during intraarterial administration of tyramine and norepinephrine. The doses were the same as those administered to the patients with postural hypotension.

During the period of observation in the Metabolic Research Ward by the same nurse observers, blood pressure was measured by the cuff-auscultatory method and pulse rate by radial artery palpation. Pulse rate and blood pressure levels were determined recumbent and sitting (and standing if possible) at half-hour intervals during waking hours. After a period of $8 \mathrm{wk}$ on a stable diet and activity program, the patients were placed on tranylcypromine, $60 \mathrm{mg} / \mathrm{day}$, in 5 divided doses. After 1 wk of tranylcypromine therapy, New York State cheddar cheese, containing approximately $1.4 \mathrm{mg}$ tyramine per gram of cheese, was started (18). Cheddar cheese was taken orally at 3-hr intervals during the patients' waking hours, for a total of 60-90 g/day. The $3 \mathrm{hr}$ interval between cheese servings was followed after noting that cheese administration during monoamine oxidase inhibition would usually elicit a pressor response lasting $2-3 \mathrm{hr}$.

\section{RESULTS}

$24 \mathrm{hr}$ urinary catecholamine fractionation in one patient, W. L., demonstrated abnormally low epinephrine and norepinephrine excretion. Total epinephrine excretion was $4.68 \mu \mathrm{g}$ and free norepinephrine $12.05 \mu \mathrm{g}$, with mean values for epinephrine and norepinephrine excretion for the patient's age being 8.7 and $57 \mu \mathrm{g}$, respectively. ${ }^{2}$

Plasma renin activity (patient W. L.) was measured during two head-up tilting maneuvers. On one occasion arterial blood pressure fell from $105 / 72$ to $62 / 54$ at $40^{\circ}$ tilt. Upon return to the recumbent position, arterial pressure increased to $120 / 84$ and returned to control levels within $10 \mathrm{~min}$. During this tilting maneuver, plasma renin activity (expressed as nanograms of angiotensin formed per milliliter per hour) levels increased from a control of 1.4 to a maximum of 6.7 , falling to control levels within $30 \mathrm{~min}$ of return to horizontal position, a normal response for this laboratory.

During another head-up tilt, recumbent blood pressure of $135 / 90$ fell to $40 / 0$ during the tilt. Upon return to horizontal an immediate hypertensive period, with blood pressure as high as $172 / 120$, ensued. Plasma renin activity increased from a control level of 1.3 to a maximum of much greater than the high standard, 8.4 (the exact value could not be determined because of the limited amount of plasma sample). Plasma renin activity levels remained elevated for more than 49 min following tilt. Elevation of plasma renin activity seemed to parallel the degree and duration of blood pressure elevation.

$24 \mathrm{hr}$ urinary aldosterone secretory rate in patient W.L. was $247.2 \mathrm{U}$ during sodium restriction; this fell

\footnotetext{
${ }^{2}$ Gaffney, T. E. Personal communication.
} 


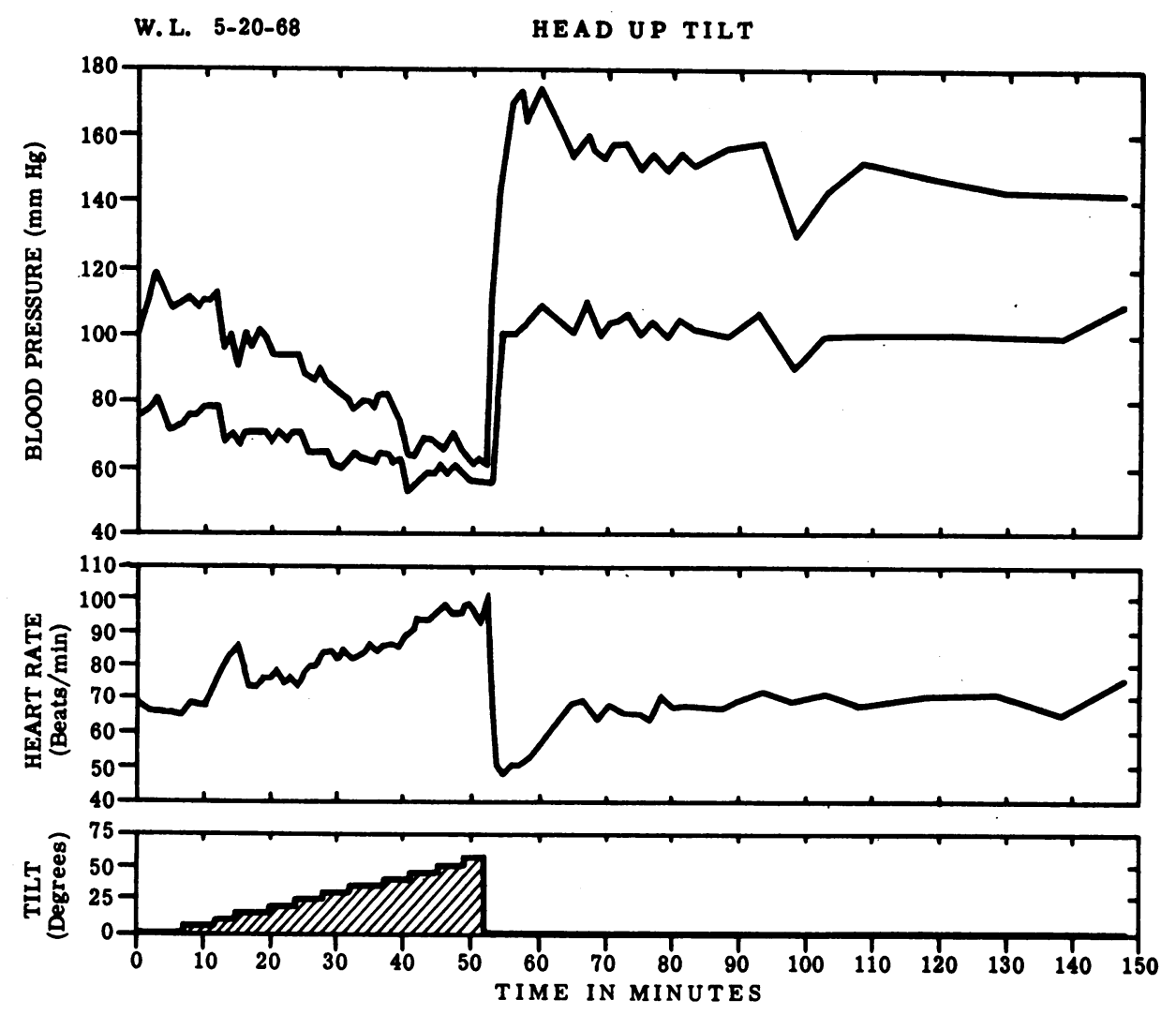

FIGURE 1 Blood pressure and heart rate responses to graded increments of head-up tilt in patient W. L.

to $74.6 \mathrm{U}$ with sodium loading. 24-hr urinary sodium excretions during these collection periods were 30 and $423 \mathrm{mEq}$, respectively.

Head-up tilt. As noted in Fig. 1, head up tilt to $60^{\circ}$ in patient W. L. was associated with a gradual fall in blood pressure from a recumbent level of $118 / 76$ to $60 / 56$. Heart rate increased only from 66 to 98 beats/min during the maneuver. Immediately upon return to horizontal, a hypertensive period with systemic blood pressure as high as 174/108 lasting 90 min was noted. During the posttilt hypertensive period, reflex bradycardia with heart rate decreasing to 48 beats per min was observed.

When W. L. was tilted during right heart catheterization, ${ }^{3}$ mean arterial pressure decreased from $94 \mathrm{~mm} \mathrm{Hg}$ at $0^{\circ}$ to $39 \mathrm{~mm} \mathrm{Hg}$ at $45^{\circ}$ tilt. Cardiac output fell correspondingly from 4.8 liters $/ \mathrm{min}$ to 2.25 liters $/ \mathrm{min}$, whereas systemic vascular resistance was $19.0 \mathrm{U}$ horizontally and $20.9 \mathrm{U}$, or essentially unchanged, at $45^{\circ}$. Graded lower body negative pressure to $-60 \mathrm{~mm} \mathrm{Hg}$ pressure caused blood pressure to fall from a control value of $104 / 76$ to $44 / 0$, again with a poststress hypertensive response. As noted in Fig. 2, forearm vascular

\footnotetext{
${ }^{3}$ Kindly performed by Dr. Harvey Feigenbaum.
}

resistance increased transiently during negative pressure, then as suction continued, fell to below the values observed before negative pressure was started.

In patient $\mathrm{C}$. H., blood pressure fell from $126 / 92$ recumbent to $68 / 52$ at $40^{\circ}$ with respective pulse rates 72 and 78 beats per min; a post-tilt hypertensive response was not noted. During lower body negative pressure, blood pressure fell from $122 / 82$ to $52 / 40 \mathrm{~mm} \mathrm{Hg}$. Calculated forearm vascular resistance gradually increased from a control value of $21 \mathrm{U}$ to $33 \mathrm{U}$.

During cold pressor tests in both patients, systolic blood pressure and forearm vascular resistance remained essentially unchanged. Forearm venous tone did not increase during deep breathing, ice on the forehead, or the Valsalva maneuver in either patient.

Intravenous atropine increased heart rate in patient W. L. from 70 to 88 beats per min without change in arterial pressure. In patient $\mathrm{C}$. H., atropine increased heart rate from 72 to 92 beats per min while recumbent blood pressure decreased transiently from a control level of $92 / 50$ to $80 / 44$.

Rhythmic supine exercise (patient W. L.) caused heart rate to increase from a resting rate of 66 per min 
L. B. N. P.

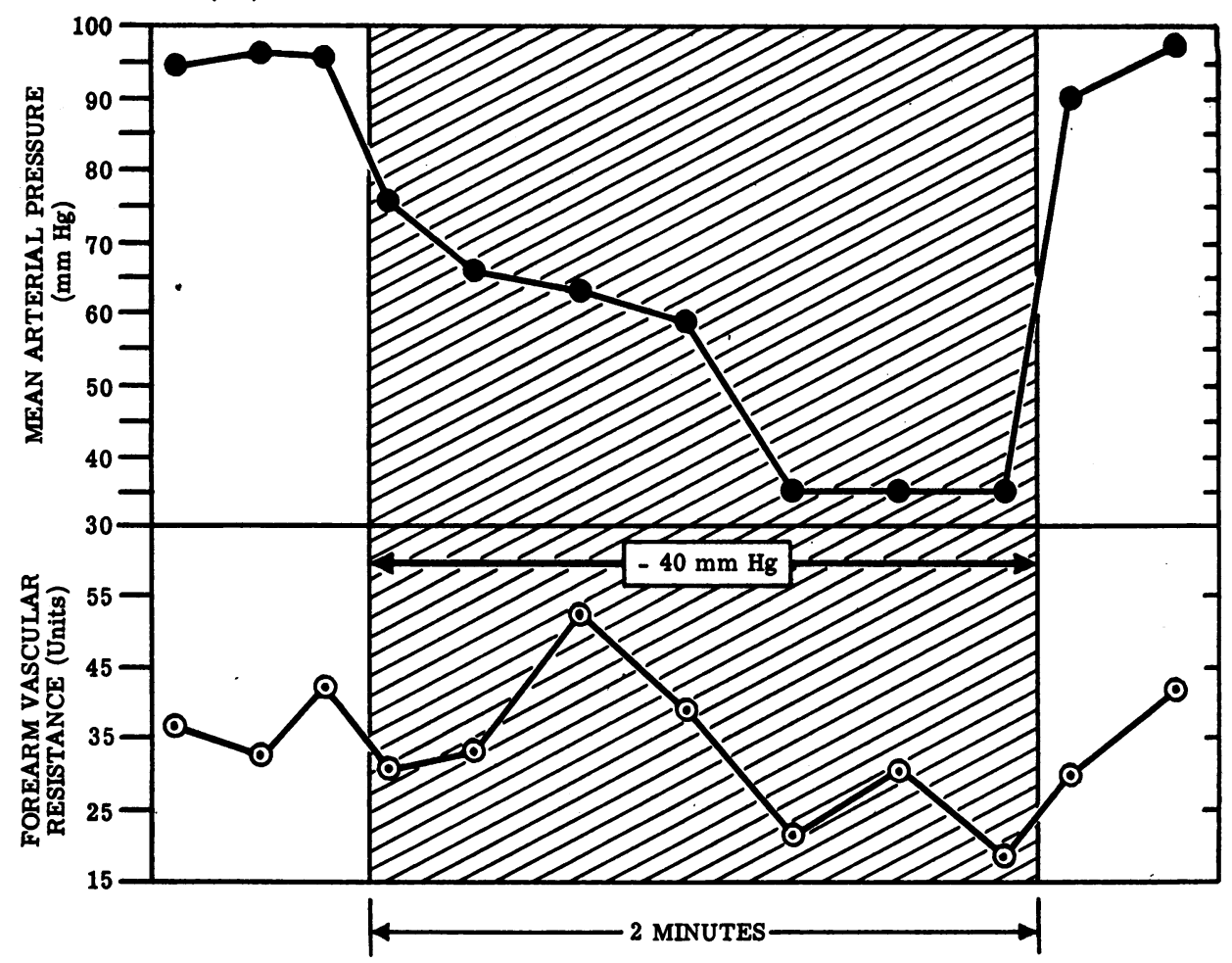

Figure 2 Mean arterial pressure and forearm vascular resistance responses to lower body negative pressure.

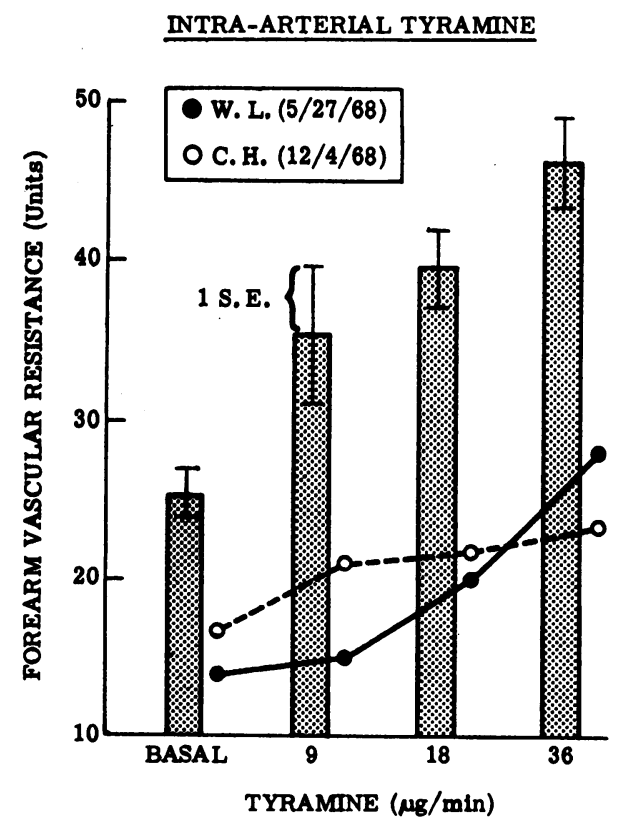

\section{INTRA-ARTERIAL NOREPINEPHRINE}

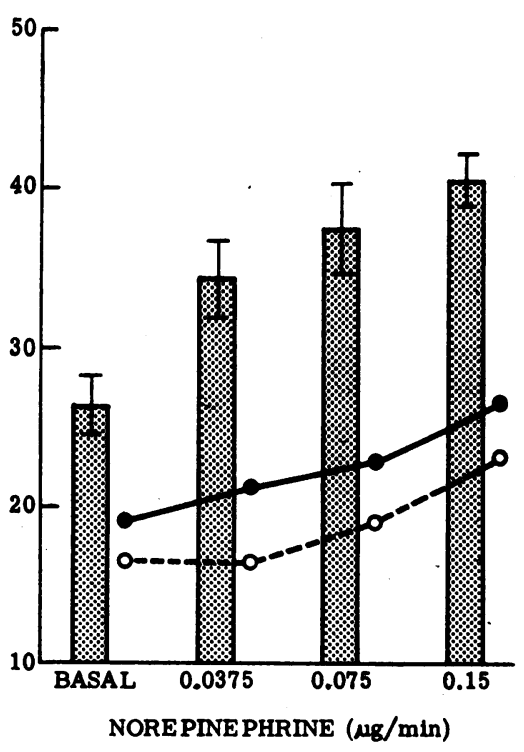

FIGURE 3 Effect of intra-arterial tyramine and norepinephrine on forearm vascular resistance. Bars represent mean forearm vascular resistance responses of normal young men. 
TABLE I

A. Intra-arterial Infusions

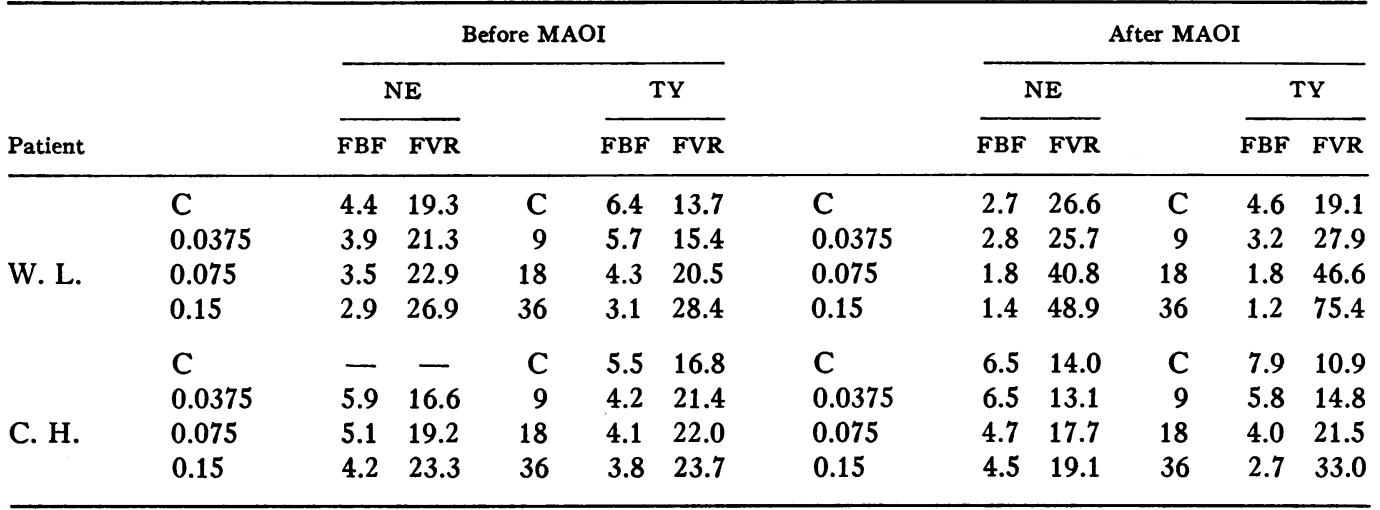

B. Intravenous Infusions

\begin{tabular}{|c|c|c|c|c|c|c|c|}
\hline \multirow[b]{2}{*}{ Patient } & & \multicolumn{3}{|c|}{ Before MAOI } & \multicolumn{3}{|c|}{ After MAOI } \\
\hline & & $\begin{array}{l}\text { NE, } \\
\text { MBP }\end{array}$ & & $\begin{array}{l}\text { TY, } \\
\text { MBP }\end{array}$ & NE & & $\begin{array}{l}\text { TY, } \\
\text { MBP }\end{array}$ \\
\hline \multirow{4}{*}{ W. L. } & $\mathrm{C}$ & 83 & C & 79 & & $\mathrm{C}$ & 72 \\
\hline & 0.0375 & 103 & 9 & 88 & & 9 & 68 \\
\hline & 0.075 & 114 & 18 & 95 & & 18 & 125 \\
\hline & 0.15 & 114 & 36 & 115 & & 36 & - \\
\hline \multirow{4}{*}{ C. $\mathrm{H}$. } & C & 86 & $\mathrm{C}$ & 107 & & $\mathrm{C}$ & 73 \\
\hline & 0.0375 & 94 & 9 & 108 & & 9 & 107 \\
\hline & 0.075 & 109 & 18 & 114 & & 18 & 120 \\
\hline & 0.15 & 115 & 36 & 135 & & 36 & - \\
\hline
\end{tabular}

Intraarterial infusions of norepinephrine and tyramine before and after administration of the monoamine oxidase inhibitor, tranylcypromine, $60 \mathrm{mg} /$ day: $\mathrm{MAOI}=$ monoamine oxidase inhibition; $\mathrm{NE}=$ norepinephrine; $\mathrm{TY}=$ tyramine $; \mathrm{FBF}=$ forearm blood flow, in $\mathrm{cc} / 100 \mathrm{cc}$ forearm volume $/ \mathrm{min} ; \mathrm{FVR}=$ forearm vascular resistance, in units; $\mathrm{C}=$ control state; $\mathrm{MBP}=$ mean arterial blood pressure. Intra-arterial infusion rates in micrograms base/min. Intravenous infusion rates in micrograms base $/ \mathrm{kg}$ body weight $/ \mathrm{min}$. Intravenous norepinephrine infusion was not repeated during monoamine oxidase inhibition. Forearm blood flow and mean blood pressure values represent 7 to 9 determinations during the 3 rd and 4 th minutes of drug infusion.

to 80 per min after 2 min work at $25 \mathrm{w}$. Heart rate increased only to 88 beats per min when the patient continued exercising to a state of marked fatigue. Blood pressure during exercise remained essentially at control levels.

The responses to intra-arterial and intravenous infusions of norepinephrine and tyramine before and after $2 \mathrm{wk}$ of tranylcypromine therapy are summarized in Table I.

Before $M A O$ inhibition. Control forearm vascular resistance levels in the two patients before intra-arterial infusions of norepinephrine and tyramine were lower but within two standard deviations of the mean forearm vascular resistance levels in quiet, recumbent normal young men (Fig. 3). During the administration of in- creasing concentrations of both agents a vasoconstrictor effect was noted, manifested by decreasing forearm blood flow and rising forearm vascular resistance.

During intravenous administration of norepinephrine and tyramine, mean blood pressure increased significantly in the two patients confirming the impression that vasopressor drugs were effective.

After MAO inhibition. The vasoconstrictor effect of intra-arterial norepinephrine was potentiated in patient W. L. 4.1 times by the administration of tranylcypromine. In $\mathrm{C}$. $\mathrm{H}$. the effect of norepinephrine administered into the brachial artery was not altered appreciably ( 0.5 -fold potentiation) by treatment with tranylcypromine.

Intra-arterial tyramine in patient W. L. was potenti- 


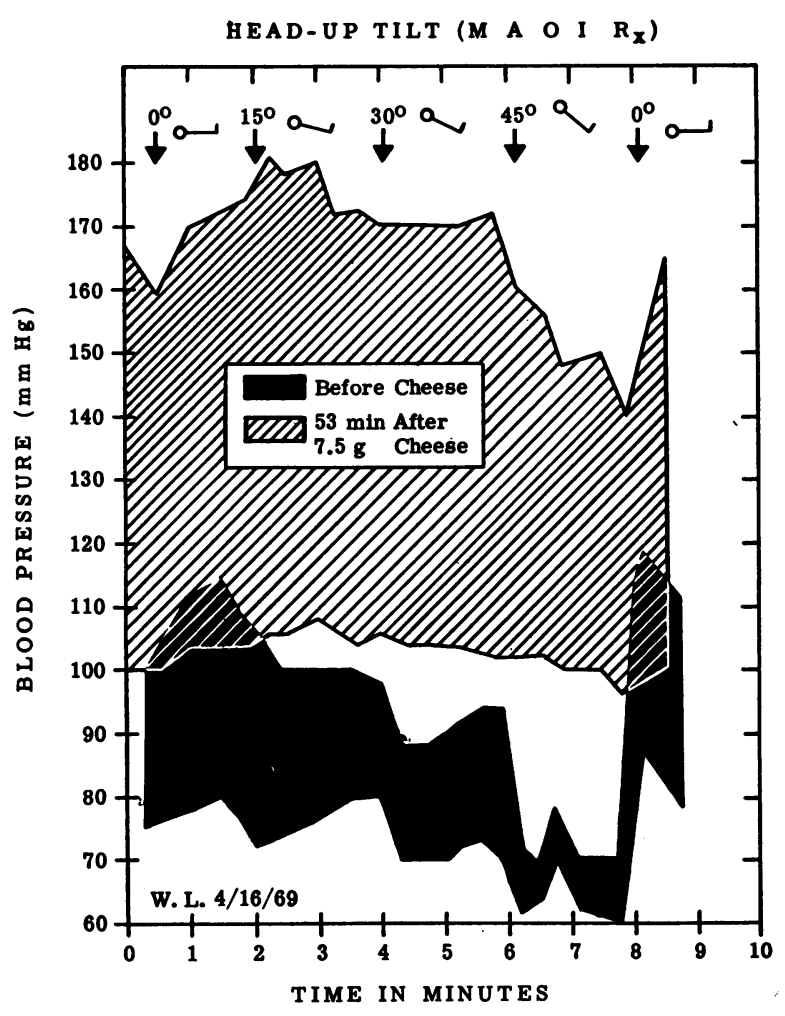

Figure 4 Blood pressure responses to head-up tilt during monoamine oxidase inhibition before and after cheddar cheese administration.

ated 3.7 times; in patient C. H. monoamine oxidase inhibition did not potentiate the action of intra-arterial tyramine (1.1-fold potentiation).

The pressor effect of tyramine, administered intravenously, was potentiated 1.2 times in patient W. L., and 1.4 times in patient $\mathrm{C}$. $\mathrm{H}$. after MAO inhibition. Thus, only slightly more tyramine was needed before MAO inhibition than after to produce similar increases in blood pressure.

Monoamine oxidase inhibitor-cheese therapy. The response of patient W. L. to combination therapy is representative of the two patients. Prior to therapy, he had been essentially limited to bed for $1 \mathrm{yr}$. Recumbent blood pressure averaged $102 / 68$ with a very rapid fall to $72 / 50$ in the sitting position. Sitting for more than $30 \mathrm{sec}$ would usually produce syncope. The acute effects of monoamine oxidase inhibition and tyramine is illustrated in Fig. 4. Before cheese, head-up tilt resulted in marked postural hypotension. $53 \mathrm{~min}$ after a $7.5 \mathrm{~g}$ serving of cheese, recumbent blood pressure was considerably higher. Tilting during the hypertensive effects of combination therapy also was associated with a modest decrease in blood pressure but not to levels that resulted in syncope.
Over a 9 month period of therapy, average recumbent blood pressure averaged $138 / 85$ and sitting pressure $99 / 70$. On this regimen the patients have been able to sit for at least $6 \mathrm{hr}$ a day, and to stand. Cerebellar ataxia and weakness have prevented walking. Combination therapy was discontinued three times over the prolonged observation period, and each time blood pressure returned to pretherapy levels. Neither cheddar cheese nor tranylcypromine, when administered singly, raised blood pressure. For a few days, the patients received ephedrine sulfate, $75 \mathrm{mg} /$ day, plus tranylcypromine. This combination induced a blood pressure rise similar to that observed with the cheese-tranylcypromine program. However, palpitations and tremulousness caused the patients to request discontinuation of the ephedrine.

\section{DISCUSSION}

The abnormal circulatory reflexes in the two patients studied raises the possibility of several defective mechanisms. Possible defects would include (a) impaired adrenergic vasoconstriction, $(b)$ the presence of an abnormal vasodilator mechanism, and $(c)$ failure of some other endocrine pressor system.

Functional impairment of the sympathetic vasomotor system is indicated by the absence of a blood pressure rise during cold pressor test, failure of reflex venoconstriction during appropriate stimuli, and in patient W. L. by the low $24 \mathrm{hr}$ urinary catecholamines. The marked drop in cardiac output in W. L. during head-up tilt may similarly be attributed to impaired venoconstriction resulting in decreased venous return.

Afferent pathways appeared to be intact because blood pressure increases induced by infusions of norepinephrine or the post-tilt hypertensive phenomenon were accompanied by appropriate reflex bradycardia. Neither patient had demonstrable impairment of somatic sensory function. By exclusion, disturbances of central integrative or peripheral efferent sympathetic pathways accounted for the impaired vasoconstrictor responses in these two patients. Anatomic evidence to support autonomic failure at a preganglionic level is derived from the studies of Johnson, Lee, Oppenheimer, and Spalding in two patients clinically similar to ours (19). A marked depletion of cells in the intermediolateral cell column of the spinal cord was found at postmortem examination. Vasoconstriction noted during intravenous and intraarterial norepinephrine infusion confirmed the presence of functional receptor sites in vascular smooth muscle. Further, the vasoconstriction observed during tyramine infusion suggested that the postganglionic sympathetic nerves contained norepinephrine. Both animal (20) and human studies $(21,22)$ indicate that the hemodynamic effects of tyramine are due to its ability to release norepinephrine from sympathetic nerve endings. 
Another mechanism which may have contributed to the severe postural hypotension is the presence of an abnormal vasodilator response. During lower body negative pressure application, and on another occasion, during head-up tilt at right heart catheterization, patient W. L. demonstrated this unexpected circulatory response. The decrease in forearm vascular resistance during LBNP and the unchanging systemic vascular resistance during head-up tilt, at a time when blood pressure was falling markedly, would indicate active vasodilatation. This phenomenon has been observed in patients with postural hypotension by others $(2,23)$. Abboud and Eckstein demonstrated that similar vasodilatation induced in normal subjects after treatment with guanethidine can be partially blocked by atropine (24). Alternatively, autoregulation of blood flow in association with a significant decrease in cardiac output could account for a decrease in forearm vascular resistance or failure to increase systemic vascular resistance during LBNP and head-up tilt. The mechanism of the vasodilator response in W. L. was not ascertained. Interestingly, the second patient $\mathrm{C}$. $\mathrm{H}$. who was less severely afflicted, did not demonstrate a vasodilator response to lower body negative pressure maneuver.

In the presence of combination therapy, LBNP in patient W. L. was associated with an increase in forearm vascular resistance from a control level of $36.2 \mathrm{U}$ to $60.1 \mathrm{U}$ at $-60 \mathrm{~mm} \mathrm{Hg}$. Therefore, the vasodilatory response in this patient during LBNP before therapy was not observed during tyramine-tranylcypromine administration. In both patients, cold pressor test repeated during the combination therapy did not produce vasoconstriction.

In normal subjects, the elevation in plasma renin activity associated with head-up tilt returns to pretilt levels within $30 \mathrm{~min}$ (25). During a tilting maneuver which did not provoke a marked hypertensive response, patient W. L.'s plasma renin response was normal. However, when an exaggerated blood pressure rise was noted during another tilting procedure, plasma renin activity was elevated for more than $49 \mathrm{~min}$ after return to recumbency. From these observations, it appears that the renin-angiotensin system is not responsible for the postural hypotension, but may be related to the posttilt pressor response. In contrast, Gordon, Kuchel, Liddle, and Island, studying a patient with amyloidosis and orthostatic hypotension, noted a failure of plasma renin activity to increase with upright posture (26).

Based upon the observation that intravenous and intraarterial tyramine could produce a pressor or vasoconstrictor response, it was assumed that the postganglionic nerve fibers contained norepinephrine. Patients receiving monoamine oxidase inhibitor drugs have experienced hypertensive crises after ingestion of foods containing tyramine, due to release of an increased amount of norepinephrine (27). A treatment regimen of a monoamine oxidase inhibitor and tyramine was cautiously begun, in an effort to convert a potentially dangerous side effect into a clinically useful therapy.

Although substantial clinical improvement occurred, one major difficulty was encountered. Pressor response to each serving of cheese was frequently erratic, resulting in considerable fluctuation in blood pressure. No dangerous elevations in blood pressure were noted with the dosages employed. We are presently unable to determine the etiology of the pressure fluctuation. Blood pressure elevation was generally related to the cheese dosage. Combination therapy did not have any effect on the patients' incoordination, bladder and bowel dysfunction, or anhydrosis.

Pharmacologic testing with intra-arterial infusions demonstrated in W. L. that 3.7 times more tyramine was required before tranylcypromine administration than after $2 \mathrm{wk}$ of this agent in order to produce similar increases in forearm vascular resistance. This implies potentiation of its action which might be due to interference with metabolism of the infused tyramine or due to altered metabolism of endogenous norepinephrine released by tyramine.

Further, the effects of intra-arterial norepinephrine and tyramine were potentiated to the same degree by monoamine oxidase inhibition. This is indicated by the fact that 4.1 times more norepinephrine was required before tranylcypromine than after treatment to give equivalent increases in forearm vascular resistance. Thus, in W. L. there appears to have been a significant inhibition of MAO-mediated intraneuronal deamination of norepinephrine. However, in C. H. treatment with tranylcypromine had no demonstrable influence on the vascular effects of either intra-arterial tyramine or norepinephrine.

Experimental evidence suggests that another mechanism by which MAO inhibitors enhance the pressor effect of tyramine is by retarding its metabolism in the liver (28). However, intravenous tyramine was not augmented by tranylcypromine in either patient; this is contrasted with the marked hypertensive response produced by oral cheese (tyramine) during monoamine oxidase inhibition. Before monoamine oxidase inhibitor therapy, oral cheese had no pressor effect. The sustained hypertension produced by the tranylcypromine-cheese combination implies that tyramine given orally was potentiated by MAO enzyme inhibition. It was therefore unexpected that intravenous tyramine was not potentiated by MAO inhibition. It can only be conjectured that tranylcypromine acted on an important source of monoamine oxidase in the intestine or portal circulation which was not accessible to tyramine administered intravenously.

Idiopathic Postural Hypotension 
The recent report by Seller, in which a tranylcypromine-hydroxyamphetamine therapeutic program was of significant value in treating another patient with idiopathic postural hypotension should be noted (29). It is important to recognize that therapy with a monoamine oxidase-cheddar cheese regimen may potentially cause dangerous elevations in blood pressure. Unexpected elevation in blood pressure could result, in part, from variation in the concentration of tyramine per gram of cheese. Caution should be exercised in initiating the program in severe cases of idiopathic postural hypotension. More conventional treatment with mineralocorticoids, high salt intake, and pressure garments should be employed first. It is important to recognize that some patients with postural hypotension may have autonomic defects involving a reduction in vascular stores of norepinephrine and thereby decreased responsiveness to tyramine (23). The effectiveness of combined monoamine oxidase inhibition and tyramine in patients other than those with the Shy-Drager syndrome remains to be demonstrated.

\section{ACKNOWLEDGMENTS}

We are indebted to Dr. François M. Abboud for constructive suggestions and review of the manuscript.

The research reported in this paper was supported in part by the Aerospace Medical Research Laboratory, Aerospace Medicine Division, Air Force Systems Command, Wright Patterson Air Force Base, Ohio, under Contract AF 33(616) 8378 with Indiana University Medical Center, by U. S. Public Health Service Grants 06308-08 and HE 02644 and by Research Career Development Award HE-28-749 (Dr. Schmid).

\section{REFERENCES}

1. Diamond, M. A., R. H. Murray, and P. Schmid. 1969. Treatment of idiopathic postural hypotension with oral tyramine (TY) and monoamine oxidase inhibitor. Clin. Res. $17: 237$.

2. Bickelmann, A. G., E. J. Lippschutz, and C. F. Brunjes. 1961. Hemodynamics of idiopathic orthostatic hypotension. Amer. J. Med. 30: 26.

3. Bannister, R., L. Ardill, and P. Fentem. 1967. Defective autonomic control of blood vessels in idiopathic orthostatic hypotension. Brain. 90: 725.

4. Page, E. B., J. B. Hickam, H. O. Sieker, H. D. McIntosh, and W. W. Pryor. 1955. Reflex venomotor activity in normal persons and in patients with postural hypotension. Circulation. 11: 262.

5. Sharpey-Shafer, E. P. 1963. Venous tone: effects of reflex changes, humoral agents and exercise. Brit. Med. Bull. 19: 145 .

6. Bevegärd, B. S., and J. T. Shepherd. 1965. Changes in tone of limb veins during supine exercise. J. Appl. Physiol. 20: 1 .

7. Shy, G. M., and G. A. Drager. 1960. A neurological syndrome associated with orthostatic hypotension. Arch. Neurol. 2: 511.

8. Hohl, R. D., B. Frame, and I. J. Schatz. 1965. The Shy-Drager variant of idiopathic orthostatic hypotension. Amer. J. Med. 39: 134.
9. Crout, J. R. 1961. Catecholamines in urine. Stand. Methods Clin. Chem. 3: 62.

10. Helmer, O. M. and W. E. Judson. 1963. The quantitative determination of renin in plasma of patients with arterial hypertension. Circulation. 27: 1050.

11. Kliman, B., and R. E. Peterson. 1960. Double isotope derivative assay of aldosterone in biological extracts. J. Biol. Chem. 235 : 1639.

12. Murray, R. H., L. J. Thompson, J. A. Bowers, and C. D. Albright. 1968. The hemodynamic effects of hypovolemia and vasodepressor syncope induced by lower body negative pressure. Amer. Heart J. 76: 799.

13. Greenfield, A. D. M., R. J. Whitney, and J. F. Mowbray. 1963. Methods for the investigation of peripheral blood flow. Brit. Med. Bull. 19: 101.

14. Schmid, P. G., J. W. Eckstein, and F. M. Abboud. 1967. Effect of $9 \alpha$-fluorohydrocortisone on forearm venous responses to norepinephrine and tyramine. J. Appl. Physiol. 23: 571.

15. Whitney, R. J. 1953. The measurement of volume changes in human limbs. J. Physiol. 121: 1.

16. Abboud, F. M., and J. W. Eckstein. 1966. Comparative changes in segmental vascular resistance in response to nerve stimulation and to norepinephrine. Circ. Res. 18: 263.

17. Finney, D. J. 1964. Statistical method in biological assay. Charles Griffin \& Co. Ltd., London. 2nd edition. 99.

18. Horwitz, D., W. Lovenberg, K. Engelman, and A. Sjoerdsma. 1964. Monoamine oxidase inhibitors, tyramine, and cheese. J. Amer. Med. Ass. 188: 1108.

19. Johnson, R. H., G. deJ. Lee, D. R. Oppenheimer, and J. M. K. Spalding. 1966. Autonomic failure with orthostatic hypotension due to intermediolateral column degeneration. Quart. J. Med. 35: 276.

20. Carlsson, A. E., E. Rosengren, A. Bertler, and J. Nilsson. 1957. Effect of reserpine on the metabolism of catecholamines. In Psychotropic Drugs. S. Garattini and V. Ghetti, editors. Elsevier, Amsterdam. 363.

21. Abboud, F. M., and J. W. Eckstein. 1964. Effects of small oral doses of reserpine on vascular responses to tyramine and norepinephrine in man. Circulation. 29: 219.

22. Mahon, W. A., and M. L. Mashford. 1963. The pressor effect of tyramine in man and its modification by reserpine pretreatment. J. Clin. Invest. 42: 338.

23. Abboud, F. M., and J. W. Eckstein. 1966. Autonomic defect in orthostatic hypotension. J. Lab. Clin. Med. 68: 851.

24. Abboud, F. M., and J. W. Eckstein. 1966. Active reflex vasodilatation in man. Fed. Proc. 25: 1611.

25. Helmer, O. 1967. Hormonal and biochemical factors controlling blood pressure. In Les Concepts de Claude Bernard sur le Milieu Interieur. Massoon et Cie, Paris. 115.

26. Gordon, R. D., O. Kuchel, G. W. Liddle, and D. P. Island. 1967. Role of the sympathetic nervous system in regulating renin and aldosterone production in man. J. Clin. Invest. 46: 599.

27. Blackwell, B. 1963. Hypertensive crisis due to monoamine oxidase inhibitors. Lancet. 2: 849.

28. Rand, M. J., and F. R. Trinker. 1968. The mechanism of the augmentation of responses to indirectly acting sympathomimetic amines by monoamine oxidase inhibitors. Brit. J. Pharmacol. Chemother. 33: 287.

29. Seller, R. H. 1969. Idiopathic postural hypotension. Report of successful treatment with a new form of therapy. Amer. J. Cardiol. $23: 838$. 